\title{
Ecological Impacts of Rainfall Regimes Changes on Agroecosystems in Southern of South America
}

ISSN: 2637-7659

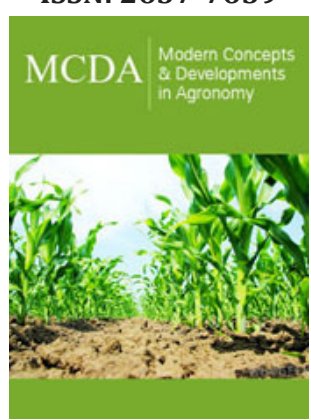

${ }^{*}$ Corresponding author: Sabattini Julian Alberto, Chair of Ecology of Agricultural Systems, Faculty of Agricultural Sciences, National University of Entre Rios. Route No. 11, Km 10. CP 3100 Oro Verde, Entre Ríos, Argentina

Submission: 㘹June 05, 2020

Published: 監July 07, 2020

Volume 6 - Issue 5

How to cite this article: Sabattini Julian Alberto, Sabattini Rafael Alberto. Ecological Impacts of Rainfall Regimes Changes on Agroecosystems in Southern of South America. Mod Concep Dev Agrono. 6(5). MCDA. 000646. 2020. DOI: 10.31031/MCDA.2020.06.000646

Copyright@ Sabattini Julian Alberto, This article is distributed under the terms of the Creative Commons Attribution 4.0 International License, which permits unrestricted use and redistribution provided that the original author and source are credited.

\section{Sabattini Julian Alberto* and Sabattini Rafael Alberto}

Chair of Ecology of Agricultural Systems, Faculty of Agricultural Sciences, National University of Entre Rios, Argentina

\begin{abstract}
Changing climate affects ecosystems in a variety of ways. As each species responds to its changing environment, its interactions with the physical world and the organisms around it change too. This A significant attention is paid to how changes in seasonal and annual precipitation sums affect ecosystems. Argentina does not escape the phenomenon of global climate change, in which numerous local references have reported the change rainfall patterns in different regions within the country. Studies that have not yet been published for the province of Entre Ríos (Argentina) are being carried out, which have allowed to demonstrate a change in the variation of monthly, seasonal and annual rainfall. The partial results confirm a sustainable increase in annual precipitation, with the 1970s being a significant breaking point. These changes have caused easily observable modifications in some of the components of ecosystems, for example: the soil and vegetation. In this manuscript the effects of climate change and a case study corresponding to typical agroecosystems of southern South America were presented. In a climate change scenario, local information is crucial to understand what the magnitude is and how the effects can be mitigated.
\end{abstract}

\section{Introduction}

\section{The global climate changes}

The world's climate is changing, and it will continue to change throughout the 21st century and beyond. Rising temperatures, new rainfall patterns, and other changes are already affecting many aspects of human society and the natural world. Climate change is transforming ecosystems on an extraordinary scale, at an extraordinary pace. As each species responds to its changing environment, its interactions with the physical world and the organisms around it change too. This triggers a cascade of impacts throughout the entire ecosystem. These impacts can include expansion of species into new areas, intermingling of formerly nonoverlapping species, and even species extinctions. Climate change is happening on a global scale, but the ecological impacts are often local and vary from place to place. Human actions have been a primary cause of the climate changes observed today. Fortunately, though, humans are also capable of changing their behavior in ways that can reduce the rate of future climate change and help wild species adapt to climate changes that cannot be avoided. How we approach other human activities that affect ecosystems, such as agriculture, water management, transportation, fishing, biological conservation, and many other activities will influence the ways and the extent to which climate change will alter the natural world-and the ecosystems on which we depend. Changing climate affects ecosystems in a variety of ways. For instance, warming may force species to migrate to higher latitudes or higher elevations where temperatures are more conducive to their survival. Similarly, as sea level rises, saltwater intrusion into a freshwater system may force some key species to relocate or die, thus removing predators or prey that are critical in the existing food chain. Climate change not only affects ecosystems and species directly, it also interacts with other human stressors such as development. Although some stressors cause only minor impacts when acting alone, their cumulative 
impact may lead to dramatic ecological changes [1]. For instance, climate change may exacerbate the stress that land development places on fragile coastal areas. Additionally, recently logged forested areas may become vulnerable to erosion if climate change leads to increases in heavy rain storms.

Ecosystems can serve as natural buffers from extreme events such as wildfires, flooding, and drought. Climate change and human modification may restrict ecosystems ability to temper the impacts of extreme conditions, and thus may increase vulnerability to damage. Examples include reefs and barrier islands that protect coastal ecosystems from storm surges, wetland ecosystems that absorb floodwaters, and cyclical wildfires that clear excess forest debris and reduce the risk of dangerously large fires [2]. In some cases, ecosystem change occurs rapidly and irreversibly because a threshold, or "tipping point", is passed. The extreme climate-related events in the South America region varies considerably due to the range of climate regimes in the region. Shifting temporal and spatial patterns of rainfall are key drivers of risk in Southern of South America. The El Niño-Southern Oscillation (ENSO) is main driver of current interannual climate variability in that region, contributing to the substantial spatial and temporal variation in extreme climate-related events. El Niño is typically associated with drier than normal conditions, and La Niña with wetter conditions. In South America, El Niño have been associated will flooding conditions, mainly the Pampas areas in Argentina. Although ENSO will remain the dominant mode of interannual variability in the future, the increased moisture availability in the atmosphere associated with climate change will likely result in the intensification of related rainfall.

Global warming affects the hydrological cycle over land, resulting in observed changes to precipitation frequency, intensity, duration and amount $[3,4]$. Although significant attention is paid to how changes in seasonal and annual precipitation sums affect ecosystems, relatively less is known about the ecological impacts of heavy rainfall events, which are being observed with increasing frequency and severity and are expected to increase in the future [4-6]. Argentina does not escape the phenomenon of global climate change, in which numerous local references have reported its effects in different regions within the country. However, we are going to make a mention of the central region of Argentina, where according to Köppen, it is characterized by a humid subtropical climate. Considering the temperature, summers are hot and humid, while winters are cool. On the other hand, rainfall is abundant in coastal areas, which decrease during a less and less humid winter as the distance from the coast increases. Those of winter are associated with storms from the west winds that run from west to east, and many summer rains occur during storm fronts that eventually cause tropical storms, registering in recent years numerous tornadoes that were not frequent. The most important agricultural activity in South America is concentrated in this region, presenting numer- ous agroecosystems such as the production of cereals (wheat, corn, sorghum), oilseeds (soybeans, sunflowers), extensive and intensive cattle farming (feedlot), among other systems less relevant productive. There they optimize the most important ecological factors that make it possible to obtain the highest productivity from these agroecosystems: the soil, the climate (particularly the seasonality of temperature and precipitation), the altitude above sea level, and the appropriate application of management techniques suitable.

\section{Case of study: Entre Ríos, Argentina}

In the last decade, a substantial change in the average climate conditions was observed in many regions of Argentina, particularly in the southern region of Mesopotamia. Qualitatively there was a change that indicated a significant increase in summer precipitation, and a decrease in the number of annual frosts, concentrating the winter season (July and August), assuming a "tropicalization of the region". As a result, numerous internal processes within the aforementioned agroecosystems were affected, severely affecting them. In this sense, studies that have not yet been published for the province of Entre Ríos are being carried out, which have allowed to demonstrate a change in the variation of monthly, seasonal and annual rainfall. To know this trend in the modification of the precipitations, historical information of the daily precipitations from the year 1945 to the present time in six localities of the central west of the province was used. Then a standardized methodology was used for the statistical processing of the information and to establish the breakpoints in the 75-year historical series. The partial results confirm a sustainable increase in annual precipitation, with the 1970 s being a significant breaking point. When the results are broken down, it is possible to identify the spring months as those significantly increased compared to the rest.

These changes have caused easily observable modifications in some of the components of ecosystems, for example: the soil and vegetation. The soil classes in this region are closely linked to the relief. The province of Entre Ríos presents a wavy to gently undulating relief, product of the withdrawal of the sea in the last glacial period. These conditions, added to certain physical properties (fine textures, fundamentally high content of clay and silt) of the soils, present a potential risk to water erosion when rainfall is abundant. The study region presents these conditions, which means that the annual increase in rainfall causes an even greater risk. However, this is aggravated when the increase in rainfall is in spring, because an important area is dedicated to agriculture and they still do not have enough vegetation cover to cushion the impact of the drop of water on the soil.

In addition, an impact on the chemical properties of the soil is to be expected, where the washing of nutrients caused by the alternations of drought-flood cycles that generate excess rainfall during the growth stage of cereals and oilseeds has been observed in certain agricultural campaigns. This directly affects crop yields 
as confirmed by reports from the region (Proyecto SIBER, Bolsa de Cereales de Entre Ríos). These hypotheses and statements are consistent with other research carried out. Rainfall changes may reduce long-term productive capacity of soil because of nutrient loss $[7,8]$. Collectively, these studies demonstrate how the temporal pattern and event size of precipitation and resulting soil moisture regime represent an important knowledge gap. Recent studies suggest that heavy rainfall caused even greater negative effects on grass reproduction and wheat yield than extreme drought $[8,9]$, which is often presumed to have the strongest and most widespread effects on terrestrial ecosystems $[10,11]$. However, except for these limited examples, little is known about heavy rainfall impacts across multiple hierarchical levels from individual plants to the ecosystem scale.

Moreover, effects have been observed in the temperate natural grasslands of southern South America, particularly those that make up the typical native forests of the region $[12,13]$. Natural grasslands are the most important forage supply in bovine farming systems. These present a growth peak that normally occurs in spring and autumn, due to the composition of the plant species that compose it, mainly C3 species. In this sense, the normal temperature and precipitation conditions have made it possible to respond to the physiological requirements of the plant species that make up the natural grassland. However, in the last decades, numerous studies have reported a change in the growth cycle [14,15], mainly attributed to a possible 'tropicalization of the climate', particularly a shift in low temperatures only in the winter months, as well as changes in precipitation regimes. The latter have modified the seasonal productivity curve of natural grasslands, as in their intrinsic diversity.

These qualitative results have not only been observed in herbaceous vegetation, but also in the shrub layer. The rainfall regimes, fundamentally, have caused the invasion of shrub species to advance, generating interspecific competition for light, water and nutrients with the herbaceous species that are consumed by cattle, sheep and horses in the mentioned region [12]. In addition, the native vegetation responds to the modification of the phenological cycles in the trees, mainly the reproductive ones of flowering and fruiting. These can be attributed to the increase in rainfall, coinciding with comments from locals living in the region. This behavior was particularly observed in species of the genus Prosopis and Vachellia that dominate in native forests, growing under semi xerophyte conditions.

Previous studies based on precipitation gradients across multiple sites or a long temporal scale at a single site usually report positive relationships of precipitation with gross ecosystem $\mathrm{CO} 2$ uptake or aboveground net primary productivity. Ecosystem benefits from increased precipitation manifest in changes across hierarchical levels, including increased metabolism (e.g. leaf photosynthesis) [16,17], improvement of soil nutrient availability [18], and resultant changes in community composition [19]. However, variability in precipitation totals over seasonal to annual scales is very different from altered incidence of heavy rainfall events, with large cumulative depths occurring over multiple consecutive days. Ecological responses to precipitation change may vary over time and depend on the persistence or recurrence of the change [17]. Plants might form 'stress memory' in physiology after a stress experience (e.g. drought), which may stabilize ecosystems; that is, ecosystems tend to remain stable when faced with climate stress if the ecosystem has previously experienced a similar stress [20,21]. Moreover, a plant may alter its morphological traits to survive under extreme water conditions, such as through changes in root: shoot ratio [22] or root and leaf structure [23]. Such an adaptation in morphology may increase an individual's tolerance to subsequent extreme conditions [24]. Therefore, it seems logical to hypothesize that responses of ecosystem structure and function to repeated (i.e. annually) heavy rainfall would change over time. However, to date, most heavy rainfall results are from opportunistic studies of events that occurred naturally without repetition (Smith, 2011). These studies are usually too short ( 1 or 2 yr) to establish a clear trajectory of change with time. As a consequence, ecological responses to recurrent heavy rainfall remain unclear.

Another aspect to consider is the impact on animals, in this case we can mention insects. Insect populations are particularly responsive to climate change because of their sensitivity to temperature, short generation times, and high flight capacity. Observations of insect herbivory on an oak lineage during Quaternary climate change indicate that there was higher damage during warm and wet periods [25]. In recent years, the magnitude and severity of epidemics have increased, with outbreak populations expanding to northern and high-elevation areas, where in the past, such disturbances were relatively rare [26-29]. Forest insect outbreaks are major disturbances by native or non-native insects, as they can be synchronous over large geographic areas and cause region-wide mortality of host trees in a relatively short period of time [26,28-30]. Disturbance due to forest insects have been recorded to increase land surface temperature and cause declines in gross primary productivity $[31,32]$.

A local example that deserves to be studied in more detail is the relationship and possible effects between the historical changes in rainfall and the founding of new colonies of leafcutting ants. If we make a qualitative association with the results obtained in the mentioned area, we can modify the behavior of the reproductive cycles of leaf cutter ants, particularly those of the Atta genus [33]. Residents frequently mention that in recent years a significant advance has been observed in the number of nests of these ants. This can be attributed to a better soil moisture condition after the nuptial flight, guaranteeing better digging conditions and development of the initial chamber $[34,35]$. However, they are hypotheses that should be tested in a timely manner. 


\section{Conclusion}

The impact of changes in rainfall regimes in different regions of the world is important to know, since it allows the development of management strategies taking into account the modifications. In this manuscript the effects of climate change and a case study corresponding to typical agroecosystems of southern South America were presented. In a climate change scenario, local information is crucial to understand what the magnitude is and how the effects can be mitigated. Although rainfall is not the only determining factor in production, it limits the range of geographic expansion. A major question will be to evaluate the simulation models of current production systems in different scenarios of climate change, and thus estimate whether the productivity of agroecosystems will change, and whether they will supply the demand for food on a global scale. In addition to this, it must be evaluated how sustainable they are productively in the face of new ways of using biomass for energy purposes, an activity recently developed worldwide and that competes with crops that are currently destined for human or animal food.

\section{References}

1. IPCC (2014) Terrestrial and Inland Water Systems. In: Climate Change 2014: Impacts, Adaptation and Vulnerability. Part A: Global and Sectoral Aspects. Contribution of Working Group II to the Fourth Assessment Report of the Intergovernmental Panel on Climate Change. Field CB (Ed.). Cambridge University Press, Cambridge, United Kingdom and New York, NY, USA.

2. Groffman PM, Kareiva S, Carter NB, Grimm J, Lawler M, et al. (2014) Ecosystems, Biodiversity, and Ecosystem Services. Chapter 8. Climate Change Impacts in the United States: The Third National Climate Assessment. Melillo JM, Richmond TC, Yohe GW (Eds.). US Global Change Research Program, USA.

3. Sherwood S, Fu Q (2014) A drier future? Science 343(6172): 737-739.

4. Stocker T (2014) Climate change 2013: the physical science basis: Working Group I contribution to the Fifth assessment report of the Intergovernmental Panel on Climate Change. Cambridge University Press, Cambridge, UK.

5. O Gorman PA, Schneider T (2009) The physical basis for increases in precipitation extremes in simulations of $21^{\text {st }}$-century climate change. Proceedings of the National Academy of Sciences 106(35): 14773-14777.

6. Otto FEL, van der Wiel K, van Oldenborgh GJ, Philip S, Kew SF, et al. (2018) Climate change increases the probability of heavy rains in Northern England/Southern Scotland like those of storm Desmond a realtime event attribution revisited. Environmental Research Letters 13: 024006.

7. Sepulveda A, Schuller P, Walling DE, Castillo A (2008) Use of ${ }^{7} \mathrm{Be}$ to document soil erosion associated with a short period of extreme rainfall. Journal of Environmental Radioactivity 99(1): 35-49.

8. Mäkinen H, Kaseva J, Trnka M, Balek J, Kersebaum KC, et al. (2017) Sensitivity of European wheat to extreme weather. Field Crops Research 222 209-217.

9. Gellesch E, Arfin Khan MAS, Jentsch A, Beierkuhnlein C (2017) Grassland experiments under climatic extremes: reproductive fitness versus biomass. Environmental and Experimental Botany 144: 68-75.

10. Reichstein M, Bahn M, Ciais P, Frank D, Mahecha MD, et al. (2013) Climate extremes and the carbon cycle. Nature 500: 287-295.

11. Frank D, Reichstein M, Bahn M, Thonicke K, Frank D, et al. (2015) Effects of climate extremes on the terrestrial carbon cycle: concepts, processes and potential future impacts. Global Change Biology 21(8): 2861-2880.
12. Sabattini RA, Wilson MG, Muzzachiodi N, Dorsch AF (1999) Guía para la caracterización de agroecosistemas del centro-norte de Entre Ríos. Revista Cientifica Agropecuaria 3: 7-19.

13. Sabattini JA, Sabattini RA, Ledesma SG (2015) Caracterización del bosque nativo del centro norte de Entre Ríos (Argentina). Agrociencia 19(2): 8-16.

14. Sabattini RA, Sabattini JA, Cian JC, Lindt MA (2018) Mechanical recovery of a native forest with shrubs of the Espinal Ecoregion (Argentina). Journal Forestist. Istanbul University 68(2): 78-86.

15. Sabattini JA, Sabattini RA, Urteaga Omar F, Bacigalupo M, Cian JC, et al. (2019) Recuperación del pastizal natural en un bosque nativo degradado del Espinal argentino: persistencia del control químico de arbustivas. Investigación Agraria 21(2): 93-107.

16. Niu S, Wu M, Han Y, Xia J, Li L, Wan S (2008) Water-mediated responses of ecosystem carbon fluxes to climatic change in a temperate steppe. New Phytologist 177(1): 209-219.

17. Ren H, Xu Z, Isbell F, Huang J, Han X, et al. (2017) Exacerbated nitrogen limitation ends transient stimulation of grassland productivity by increased precipitation. Ecological Monographs 87(3): 457-469.

18. Lu XT, Dijkstra FA, Kong DL, Wang ZW, Han XG (2014) Plant nitrogen uptake drives responses of productivity to nitrogen and water addition in a grassland. Scientific Report 4: 4817.

19. Knapp AK, Briggs JM, Smith MD (2012) Community stability does not preclude ecosystem sensitivity to chronic resource alteration. Functional Ecology 26(6): 1231-1233.

20. Walter J, Jentsch A, Beierkuhnlein C, Kreyling J (2013) Ecological stress memory and cross stress tolerance in plants in the face of climate extremes. Environmental and Experimental Botany 94: 3-8.

21. Backhaus S, Kreyling J, Grant K, Beierkuhnlein C, Walter J, et al. (2014) Recurrent mild drought events increase resistance toward extreme drought stress. Ecosystems 17(6): 1068-1081.

22. Cheng J, Chu P, Chen D, Bai Y (2016) Functional correlations between specific leaf area and specific root length along a regional environmental gradient in Inner Mongolia grasslands. Functional Ecology 30(6): 985997.

23. Insausti P, Grimoldi A, Chaneton E, Vasellati V (2001) Flooding induces a suite of adaptive plastic responses in the grass Paspalum dilatatum. New Phytologist 152(2): 291-299.

24. Wang S, Callaway RM, Zhou DW, Weiner J 2017) Experience of inundation or drought alters the responses of plants to subsequent water conditions. Journal of Ecology 105(1): 176-187.

25. Su T, Adams JM, Wappler T, Huang YJ, Jacques FMB, et al. (2015) Resilience of plant-insect interactions in an oak lineage through quaternary climate change. Paleobiol 41(1): 174-186.

26. Raffa KF, Aukema BH, Barbara J, Bentz BJ, Carroll AL, et al. (2008) Crossscale drivers of natural disturbances prone to anthropogenic amplification: the dynamics of bark beetle eruptions. Bioscience 58(6): 501-517.

27. Pureswaran DS, De Grandpré LD, Paré D, Taylor A, Barrette M, et al. (2015) Climate-induced changes in host tree-insect phenology may drive ecological state-shift in boreal forests. Ecology 96(6): 1480-1491.

28. Myers JH, Cory JS (2013) Population cycles in forest Lepidoptera revisited. Annu Rev Ecol Evol Syst 44: 565-592.

29. Allstadt AJ, Haynes KJ, Liebhold AM, Johnson DM (2013) Long-term shifts in the cyclicity of outbreaks of a forest-defoliating insect. Oecologia 172(1): 141-151.

30. Williams DW, Liebhold AM (2002) Climate change and the outbreak ranges of two north American bark beetles. Agric For Entomol 4: 87-99.

31. Cooper LA, Ballantyne AP, Holden ZA, Landguth EL (2017) Disturbance impacts on land surface temperature and gross primary productivity in the western United States. J Geophys Res Biogeosci 122(4): 930-946. 
32. Williams CA, Gu H, MacLean R, Masek JG, Collatz GJ (2016) Disturbance and the carbon balance of US forests: a quantitative review of impacts from harvests, fires, insects, and droughts. Glob Planet Chang 143: 6680 .

33. Sabattini JA, Zerda H, Sabattini RA, Savino C (2017) Distribución geográfica potencial de Atta vollenweideri Forel en la provincia de Entre Ríos (Argentina). Ambiencia 13(1): 31-46.
34. Jepsen JU, Biuw M, Ims RA, Kapari L, Schott T, et al. (2013) Ecosystem impacts of a range expanding forest defoliator at the forest-tundra ecotone. Ecosystems 16(4): 561-75.

35. Marzen M, Iserloh T, de Lima JL, Fister W, Ries JB (2017) Impact of severe rain storms on soil erosion: experimental evaluation of wind-driven rain and its implications for natural hazard management. Science of the Total Environment 590-591: 502-513. 